\title{
The Development of a Cancer-Related Cognitive Impairments Seminar for Occupational Therapy Practitioners
}

\author{
Sara S. Ulfers \\ UnityPoint Health-Des Moines \\ Christine Berg \\ Washington University in St. Louis
}

Follow this and additional works at: https://encompass.eku.edu/jote

Part of the Adult and Continuing Education Commons, and the Occupational Therapy Commons

\section{Recommended Citation}

Ulfers, S. S., \& Berg, C. (2019). The Development of a Cancer-Related Cognitive Impairments Seminar for Occupational Therapy Practitioners. Journal of Occupational Therapy Education, 3 (2). https://doi.org/10.26681/jote.2019.030207

This Original Research is brought to you for free and open access by the Journals at Encompass. It has been accepted for inclusion in Journal of Occupational Therapy Education by an authorized editor of Encompass. For more information, please contact Linda.Sizemore@eku.edu. 


\title{
The Development of a Cancer-Related Cognitive Impairments Seminar for Occupational Therapy Practitioners
}

\begin{abstract}
Occupational therapy practitioners are qualified to address the emergence of functional deficits from cancerrelated cognitive impairments (CRCI); however, they have reported a need to address gaps in their knowledge of CRCI. The purpose of this study was to comprehensively design, disseminate and examine the impact of implementing a face-to-face continuing education seminar designed to enhance occupational therapy practitioners' knowledge of CRCI in adults and older adults. After completing a needs assessment and designing the seminar, the seminar was piloted with occupational therapy students $(n=64)$ where student feedback guided modifications to the seminar's content, design and evaluation. The final CRCI seminar was presented at 15 facilities throughout the continuum of care with 130 occupational therapy practitioners. Participants' CRCI knowledge increased significantly after the seminar $(Z=-9.623$, p performance $(96 \%, n=$ $123)$ and perceived patient outcomes $(94 \%, n=119)$ in the future. The seminar was both an effective method for increasing practitioners' short-term CRCI knowledge and a well-received method of dissemination.
\end{abstract}

\section{Keywords}

Cognition, continuing education, knowledge translation, survivorship

\section{Creative Commons License} (c) (1) ()

This work is licensed under a Creative Commons Attribution-Noncommercial-No Derivative Works 4.0 License.

\section{Acknowledgements}

Special thanks to Jaya Bhakta, Allison King, Regina Abel, Peggy Barco, Meghan Doherty, and Benjamin Harlander for their assistance with this project. 


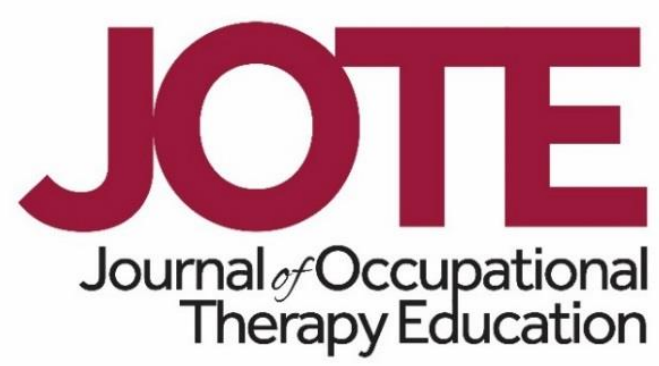

Volume 3, Issue 2

\title{
The Development of a Cancer-Related Cognitive Impairments
}

\section{Seminar for Occupational Therapy Practitioners}

\author{
Sara Ulfers, OTD, OTR/ $\mathrm{L}^{1}$ and Christine Berg, $\mathrm{PhD}, \mathrm{OTR} / \mathrm{L}^{2}$
}

UnityPoint Health-Des Moines at lowa Methodist Medical Center ${ }^{1}$

Washington University²

United States

\begin{abstract}
Occupational therapy practitioners are qualified to address the emergence of functional deficits from cancer-related cognitive impairments (CRCl); however, they have reported a need to address gaps in their knowledge of $\mathrm{CRCl}$. The purpose of this study was to comprehensively design, disseminate and examine the impact of implementing a faceto-face continuing education seminar designed to enhance occupational therapy practitioners' knowledge of $\mathrm{CRCl}$ in adults and older adults. After completing a needs assessment and designing the seminar, the seminar was piloted with occupational therapy students $(n=64)$ where student feedback guided modifications to the seminar's content, design and evaluation. The final $\mathrm{CRCl}$ seminar was presented at 15 facilities throughout the continuum of care with 130 occupational therapy practitioners.

Participants' CRCI knowledge increased significantly after the seminar $(Z=-9.623$, $\mathrm{p}<.001)$. The majority of participants anticipated that this knowledge will positively affect their performance $(96 \%, n=123)$ and perceived patient outcomes $(94 \%, n=119)$ in the future. The seminar was both an effective method for increasing practitioners' shortterm $\mathrm{CRCl}$ knowledge and a well-received method of dissemination.

\section{INTRODUCTION}

With the advancement of screening and medical treatments, the number of cancer survivors is increasing (Denlinger, Carlson, et al., 2014; Mariotto, Yabroff, Shao, Feuer, \& Brown, 2011). Estimates indicate that by 2020, over 18 million cancer survivors will live in the United States (Mariotto et al., 2011; Siegel et al., 2012). One survivorship side effect that adult and older adult cancer survivors can experience is cancer-related cognitive impairments $(\mathrm{CRCl})$, which refer to cognitive changes that can occur before,
\end{abstract}


during, or after cancer treatment (Ahles, Root, \& Ryan, 2012; Ahles, Schagen, \& Vardy, 2012).

Recent literature suggests that $17-75 \%$ of cancer survivors experience cognitive changes during treatment, and up to $35 \%$ of adult cancer survivors will experience longterm cognitive changes (Ahles, Root, et al., 2012; Ahles, Schagen, et al., 2012). The emergence of $\mathrm{CRCl}$ may lead to a disruption in important roles, routines, and activities, such as returning to work, caregiving, or driving (Boykoff, Moieni, \& Subramanian, 2009; Edelstein \& Bernstein, 2014; Reid-Arndt, Hsieh, \& Perry, 2010). Occupational therapy practitioners are distinctly qualified to address $\mathrm{CRCl}$ by providing cognitive strategies to cancer survivors to facilitate occupational engagement (Pergolotti, Williams, Campbell, Munoz, \& Muss, 2016). Specifically, the National Cancer Comprehensive Network (NCCN) identified occupational therapy as an important referral source for addressing functional limitations that emerge from CRCl (Denlinger, Ligibel, et al., 2014).

Although occupational therapy practitioners are qualified to address the functional deficits of CRCl (Denlinger, Ligibel, et al., 2014; Pergolotti et al., 2016), a recent needs assessment demonstrated that occupational therapy practitioners had perceived gaps in their knowledge about $\mathrm{CRCl}$, and they perceived a need for more clinically relevant CRCl evidence (Ulfers \& Berg, 2017). It is essential to first address practitioners' knowledge needs by disseminating recent, clinically relevant $\mathrm{CRCl}$ literature to practitioners before expecting practitioners to integrate evidence-based practice when addressing the dynamic needs of survivors of cancer.

Face-to-face continuing education, also referred to as continuing competency programs within the occupational therapy profession ("Standards for Continuing Competence," 2015), is an established method for improving practitioners' knowledge and skills (Forsetlund et al., 2009). However, there is currently a paucity of literature describing the development, dissemination, and evaluation of the effectiveness of a CRCl continuing competency seminar. It is necessary to understand the short-term impact of a continuing competency program in order to guide future studies that examine practitioners' long-term knowledge retention and the impact of continuing competency seminars on patient outcomes.

The purpose of this study was to comprehensively design, disseminate and examine the impact of implementing a face-to-face continuing education seminar designed to enhance occupational therapy practitioners' knowledge of $\mathrm{CRCl}$ in adults and older adults.

\section{METHODS}

This study employed an exploratory approach that was conducted in three phases: (1) seminar development based on findings from a needs assessment, (2) pilot of the seminar to a convenience sample of occupational therapy students, and (3) delivery of the seminar to occupational therapy practitioners (see Figure 1). To optimize seminar development, a multidisciplinary group of professionals who were well versed in instrument development, program development, educational research, oncology, and 
occupational therapy were consulted during the seminar development phase. All phases of this study were reviewed and approved by the Washington University in St. Louis Institutional Review Board and Protocol Review Monitoring Committee at Siteman Cancer Center.

\section{Phase 1: Seminar Development}

Seminar content and design developed based off of $\mathrm{CRCl}$ informational needs identified by occupational therapy practitioners.

Seminar evaluation surveys developed and peer reviewed.

\section{Phase 2: Seminar Piloted to Students}

Seminar piloted to a convenience sample of second-year occupational therapy graduate students $(n=64)$.

Student feedback guided minor modifications made to the seminar's content, design, and evaluation surveys.

\section{Phase 3: Seminar Delivered to Practitioners}

Seminar disseminated to occupational therapy practitioners $(n=130)$ at fifteen facilities across the continuum of care.

Figure 1. Program overview.

\section{Phase 1: Seminar Development}

Needs assessment. In an earlier phase of this study, a nationwide needs assessment survey employing a snowball sampling approach was disseminated to occupational therapy practitioners throughout the continuum of care to examine their knowledge gaps and needs pertaining to their $\mathrm{CRCl}$ (Ulfers \& Berg, 2017). Of the 107 total respondents, the majority $(n=97,91 \%)$ selected it would be beneficial to attend a face-to-face continuing education program. Within the survey, practitioners selected their preferred modes of delivery, such as PowerPoint presentation ( $n=93,87 \%)$ or videos from individuals with $\mathrm{CRCI}(n=78,73 \%)$. Practitioners also selected topics that would be "very useful" to cover within the seminar, such as potential causes of $\mathrm{CRCl}(n=50$, $47 \%$ ), understanding neuropsychology's role versus occupational therapy's role ( $n=64$, $60 \%)$, recommended cognitive assessments $(n=73,68 \%)$ and recommended intervention approaches $(n=84,79 \%)$. Practitioners had the opportunity to suggest additional topics to cover, methods of delivery, and additional considerations to be implemented in a future $\mathrm{CRCl}$ seminar. For example, several practitioners wrote that it would be beneficial for the seminar to include handouts. Results from this needs assessment guided the content, design and key resources included in the $\mathrm{CRCl}$ seminar. For a more comprehensive examination of the needs assessment, see Ulfers and Berg, 2017. 


\section{Seminar design and development.}

Guiding theoretical framework. Principles from Malcolm Knowles' Andragogy Theory served as the guiding theoretical framework for the seminar design. Principles include the learner's: (1) needs to know, (2) prior experiences (foundation), (3) readiness to learn, (4) orientation to learning, (5) self-concept, and (6) motivation to learn (Knowles, Holton, \& Swanson, 2014). A description of how the seminar incorporated Knowles' Andragogy Theory is shown in Table 1.

Table 1

Description and Application of Knowles' Andragogy Theory for Development of the Seminar

\begin{tabular}{|c|l|l|}
\hline Principle & \multicolumn{1}{|c|}{ Explanation of Principle } & $\begin{array}{l}\text { Application of Principle to Seminar } \\
\text { Development }\end{array}$ \\
\hline $\begin{array}{c}\text { Learner's } \\
\text { needs to } \\
\text { know }\end{array}$ & $\begin{array}{l}\text { Many adults want to know } \\
\text { the rationale for why it is } \\
\text { important to learn the } \\
\text { content. }\end{array}$ & $\begin{array}{l}\text { The seminar had specific } \\
\text { objectives that outlined the } \\
\text { importance of the topic. }\end{array}$ \\
& $\begin{array}{l}\text { As participation in the seminar was } \\
\text { voluntary, practitioners were able } \\
\text { to self-identify if the content would } \\
\text { be pertinent to populations they } \\
\text { encounter. }\end{array}$ \\
& $\begin{array}{l}\text { The seminar had several sections } \\
\text { specifically identifying the } \\
\text { importance of learning the content } \\
\text { (e.g. recommended assessments). }\end{array}$ \\
\hline $\begin{array}{l}\text { Learner's } \\
\text { prior } \\
\text { experience }\end{array}$ & $\begin{array}{l}\text { As adults age, they } \\
\text { accumulate more life } \\
\text { experience that can impact } \\
\text { learning. }\end{array}$ & $\begin{array}{l}\text { Practitioners were asked about } \\
\text { their prior experiences with the } \\
\text { population and clinical settings in } \\
\text { which they encountered survivors } \\
\text { of cancer. }\end{array}$ \\
& $\begin{array}{l}\text { Practitioners had an opportunity to } \\
\text { participate in group discussion at } \\
\text { the seminar to share with other } \\
\text { practitioners their experiences with } \\
\text { the population which may lead to } \\
\text { the adoption of new information. }\end{array}$ \\
\hline
\end{tabular}




\begin{tabular}{|c|c|c|}
\hline $\begin{array}{l}\text { Learner's } \\
\text { readiness to } \\
\text { learn }\end{array}$ & $\begin{array}{l}\text { As adults age, they become } \\
\text { more interested in learning } \\
\text { topics that are pertinent to } \\
\text { their lives. }\end{array}$ & $\begin{array}{l}\text { - The needs assessment asked } \\
\text { participants to identify topics of } \\
\text { interest, which were subsequently } \\
\text { integrated into the seminar. } \\
\text { - The seminar was developed } \\
\text { specifically for occupational } \\
\text { therapists; content was directly } \\
\text { pertinent to practice (e.g. } \\
\text { assessments, interventions). } \\
\text { - The seminar was scheduled at a } \\
\text { time that aligned with the majority } \\
\text { of practitioners' schedules (e.g. the } \\
\text { majority scheduled during their } \\
\text { lunch hour to learn to cater to busy } \\
\text { schedules). } \\
\text { - The seminar was designed to be } \\
\text { presented at the facility to cater to } \\
\text { practitioners who may have a lack } \\
\text { of time to keep current with } \\
\text { literature. }\end{array}$ \\
\hline $\begin{array}{l}\text { Learner's } \\
\text { orientation } \\
\text { to learning }\end{array}$ & $\begin{array}{l}\text { Adults' preferences for } \\
\text { learning content that is more } \\
\text { subject-centered versus } \\
\text { problem-centered. As adults } \\
\text { age, most adults are more } \\
\text { problem-centered. }\end{array}$ & $\begin{array}{l}\text { The seminar was designed to } \\
\text { appeal to a variety of learning } \\
\text { styles, such as PowerPoint or } \\
\text { handouts. The seminar included } \\
\text { videos where a survivor of cancer } \\
\text { who received occupational therapy } \\
\text { identified instrumental activities of } \\
\text { daily living and activities of daily } \\
\text { living that were interrupted as a } \\
\text { result of cancer treatment. }\end{array}$ \\
\hline $\begin{array}{l}\text { Learner's } \\
\text { self-concept }\end{array}$ & $\begin{array}{l}\text { The adults' initiative to learn. } \\
\text { Adults are on a spectrum of } \\
\text { being a dependent learner to } \\
\text { being completely self- } \\
\text { directed. }\end{array}$ & $\begin{array}{l}\text { The topics presented were directly } \\
\text { relevant to clinical practice; } \\
\text { therefore, the seminar provided the } \\
\text { opportunity for the learner to take } \\
\text { initiative to learn content that is } \\
\text { applicable to patient care. }\end{array}$ \\
\hline $\begin{array}{l}\text { Learner's } \\
\text { motivation } \\
\text { to learn }\end{array}$ & $\begin{array}{l}\text { As adults age, they become } \\
\text { more motivated to learn by } \\
\text { internal incentives (curiosity, } \\
\text { satisfaction with content, } \\
\text { etc.) versus external } \\
\text { requirements (increase in } \\
\text { pay). }\end{array}$ & $\begin{array}{l}\text { - The seminar counted toward } \\
\text { continuing education credits } \\
\text { necessary for maintaining } \\
\text { professional licensure. This helped } \\
\text { to motivate learners. }\end{array}$ \\
\hline
\end{tabular}


Seminar content. A literature review was conducted on the topics identified in the needs assessment: (1) general cancer survivorship, (2) prevalence of $\mathrm{CRCl}$, (3) duration of $\mathrm{CRCl}$ persistence, (4) clinical presentation and affected cognitive domains, (5) proposed mechanisms and risk factors of $\mathrm{CRCl}$, (6) differentiation of neuropsychology and occupational therapy roles in assessing $\mathrm{CRCl},(7)$ cognitive assessments, (8) cognitive interventions, (9) community resources for clients and (10) supportive resources for practitioners.

Seminar design. Based on findings of the needs assessment, a PowerPoint Presentation served as the primary framework for delivering $\mathrm{CRCl}$ information. However, lecture, group interaction, videos and handouts were also included in the seminar to address a variety of different learning styles. The seminar was designed to last approximately 50-60 minutes and delivered at participants' work place facilities in order to cater to working practitioners' schedules.

\section{Phase 2: Seminar Piloted to Students}

Before disseminating to clinicians, a convenience sample of 94 occupational therapy graduate students were recruited to pilot the seminar. Inclusion criteria included: (1) presently enrolled as a second-year graduate student in the occupational therapy program, and (2) attending class on both dates that the pre-test (one week prior to the seminar) and the post-test (day of the seminar) were administered. The pilot had two primary purposes: (1) to deliver information about $\mathrm{CRCl}$ in a course that focused on cognitive interventions, and (2) to identify challenges in the content and delivery of the seminar and make modifications to improve the seminar prior to presenting to practitioners.

Instrumentation. To evaluate the effectiveness of the seminar, an 18-item, multiplechoice and true/false pre/post-test to assess $\mathrm{CRCl}$ knowledge (e.g., general presentation and persistence information, proposed causes, recommended assessments and interventions) was designed. A five-item seminar evaluation survey was designed to assess the following: whether the seminar better prepared students (targeted population for the pilot) to treat the oncology population in the future (5-item Likert scale; strongly agree to strongly disagree), the perceived effectiveness of the seminar presentation (5-item Likert scale), the perceived usefulness of topics discussed in the seminar (5-item Likert scale), and perceived strengths and weaknesses of the seminar (open response).

Procedure. Ninety-four students enrolled in the occupational therapy graduate course were informed of the seminar on the course syllabus and sent a recruitment email regarding the purpose of the seminar. Participants signed the informed consent document and completed the $\mathrm{CRCl}$ knowledge pre-test one week prior to the seminar. After the seminar, participants immediately completed the $\mathrm{CRCl}$ knowledge post-test and the seminar evaluation survey. 
The primary professor of the course and research team members remained blind to students' participation in the study. Students did not receive any compensation for participating in the study, and participation had no impact on their grades in the course.

Statistical analysis. The $\mathrm{CRCl}$ knowledge pre/post-test scores were entered into SPSS version 23 and analyzed using descriptive and inferential statistics (IBM Corp, 2013). Responses on the seminar evaluation survey were analyzed using descriptive statistics and open-ended responses were categorized to further inform changes to the seminar.

Results. Of the 94 second-year students who were approached, 68 (72\%) completed the $\mathrm{CRCl}$ knowledge pre/post-test and the seminar program evaluation. Using a Wilcoxon signed ranks test, participants demonstrated a significant knowledge gain $(Z=$ $-6.899, \mathrm{p}<.001)$ from the $\mathrm{CRCl}$ knowledge pre-test $(\mathrm{M}=8.68 ; \mathrm{SD}=1.79)$ to the $\mathrm{CRCl}$ knowledge post-test $(\mathrm{M}=13.32 ; \mathrm{SD}=2.78)$.

From the seminar evaluation survey, the majority of participants ( $n=54,82 \%)$ "agreed" or "strongly agreed" that the seminar was effectively presented, and $92 \%(n=61)$ "agreed" or "strongly agreed" they felt better prepared to address the needs of the oncology population in the future. Additionally, four categories were identified based on open-ended responses for modifying the seminar before presenting to practitioners: (1) improvements to design and structure by simplifying content on the slides $(n=52) ;(2)$ improving the presenter's delivery of the content ( $n=23)$; (3) including additional content of interest ( $n=19)$; and (4) elaboration of resources included on the handout $(n=6)$.

\section{Phase 3. Seminar Delivery to Occupational Therapy Practitioners}

Participants. A convenience sample list of emails belonging to contacts at adult and older adult healthcare facilities in the greater St. Louis region (within a 20-mile radius) that employed registered occupational therapists and certified occupational therapy assistants throughout the continuum of care was generated, and a total of 23 facilities were identified. Personnel at these facilities were contacted to determine their interest in a $\mathrm{CRCl}$ continuing competency seminar for occupational therapy practitioners that would offer one contact hour of free continuing education. Once a facility approved and committed to participating in the seminar, facility personnel were responsible for informing practitioners of the time, date, and seminar information. The research team was not involved with the clinician recruitment process after scheduling the seminar. Participant inclusion criteria were: (1) possesses occupational therapy licensure, (2) presently practicing as an occupational therapist or occupational therapy assistant, (3) fluent in the English language.

Instrumentation. Based on the initial pilot to students, modifications were made to the seminar evaluation tools. During the pilot to students, the seminar evaluation took approximately twenty to twenty five minutes. Because practitioners would have only one hour to complete the seminar and evaluation tools, the $\mathrm{CRCl}$ knowledge pre/posttest was condensed from 18 to 10 items to encourage participation (see Appendix A). 
Because the previous seminar evaluation survey was tailored for students, the seminar evaluation survey was additionally modified to be more clinically pertinent to practitioners. The revised seminar evaluation additionally assessed: (1) perceived satisfaction (5-item Likert scale; strongly agree to strongly disagree), (2) perceived effectiveness of seminar presentation (5-item Likert scale; strongly agree to strongly disagree), and (3) perceived impact of the seminar on clinicians' competence, performance, and patient outcomes (3-item Likert scale; no impact, moderate impact, or great impact).

Procedure. To improve the seminar content before presenting it to practitioners, modifications were made to incorporate feedback from student participants' seminar evaluations and performance on CRCl knowledge pre/post-tests. Minor modifications included: (1) particular slides were simplified, (2) additional information was added to the assessments and interventions sections of the seminar as students identified they wanted more information on these topics, and (3) the handout was expanded to include more information that practitioners would be able to reference in the future.

The seminar was presented face-to-face at each facility and lasted approximately one hour. Participants provided initials on a consent information sheet and completed the 10-item $\mathrm{CRCl}$ knowledge pre-test prior to the seminar. Immediately following the seminar, participants completed the $\mathrm{CRCl}$ knowledge post-test and the seminar evaluation survey. Regardless of participation in the study, all attendees of the seminar received one free continuing competency credit for attending the seminar.

Statistical analysis. SPSS version 23 was used for all descriptive and inferential analyses (IBM Corp, 2013). The level of significance was set at .05. Descriptive analyses were used to describe participant characteristics. Nonparametric statistics were used for ordinal data. Wilcoxon signed rank test was used for within-subject analyses for the knowledge pre/post-test, and a Mann-Whitney $U$ test was used to compare baseline scores. Open-ended responses were categorized based off of frequencies.

\section{RESULTS}

Of the 23 facilities invited, 15 (65\%) facilities through the continuum of care agreed to host the continuing competency seminar. Of the 140 occupational therapy practitioners who attended the seminar, three did not provide consent and seven did not complete the pre-test, leaving 130 (93\%) participants included in data analysis. Table 2 shows the demographic profile of the participants in terms of their professional credentials, years of practice at their current setting, total years of practice, previously encountered oncology population during clinical practice (yes/no), and present clinical setting in the continuum of care. 
Table 2

Demographic Characteristics of Participants

\begin{tabular}{ll}
\hline Variables & $\mathbf{n}(\%)$ \\
\hline Total & $130(100)$ \\
\hline Practitioner & \\
$\quad$ OTR & $110(85)$ \\
COTA & $20(15)$ \\
\hline Present primary setting & \\
Acute care & $41(32)$ \\
Inpatient rehabilitation & $38(29)$ \\
Skilled nursing facility & $12(9)$ \\
Outpatient & $9(7)$ \\
Community & $20(15)$ \\
Home health & $10(8)$ \\
\hline
\end{tabular}

\begin{tabular}{ll}
\hline Number of years in current setting & \\
Mean \pm SD, range & $6.6,0-25$ \\
Median & 4.8 \\
\hline
\end{tabular}

Total number years practicing

Mean \pm SD, range $\quad 11.2 \pm 9.6,0-37$

Median $\quad 8.0$

\section{Oncology population experience}

Yes

$104(87)$

No

$15(13)$

Note. OTR $=$ Registered occupational therapist; COTA = certified occupational therapy assistant

Impact of the Educational Seminar on Short-Term CRCI Knowledge

Using a Wilcoxon signed-ranks test, a significant increase in $\mathrm{CRCl}$ knowledge from the pre-test to the post-test $(Z=-9.623, p<.001)$ was found. Across all conditions, participants demonstrated significant increases in post-test scores after participating in the seminar (see Table 2).

A Mann-Whitney $U$ test was utilized to compare pre-test and post-test scores across demographic variables (see Table 3). There were no significant differences $(p>.05)$ in the pre-test scores for all demographic variables (see Table 2). However, occupational therapists scored significantly higher than certified occupational therapy assistants on the knowledge post-test $(U=647.00, p=.003)$. Using a Kruskal-Wallis analysis, there 
was also significant difference across continuum of care settings on the post-test $(H=14.556, p=.012)$. Because sample sizes were larger than five, the Kruskal Wallis test compared the test statistic $(\mathrm{H})$ to a critical value derived from a chi squared distribution (rather than calculating the exact probabilities); in this analysis the critical value from the chi square distribution was 11.07 and $H$ was 14.56; further highlighting that there was a significant difference in post-test scores between continuum of care settings. The following demographic conditions resulted in no significant differences on post-test scores: years at current setting, total years of practice, and experience encountering oncology population in clinical practice (see Table 2).

A Wilcoxon signed-ranks test was used for individual question analysis. Participants demonstrated significant improvement between the pre-test and post-test for all but one item. Improvement in two items were particularly interesting and relevant to clinical practice. First, $30 \%$ ( $n=39$ ) of participants correctly answered that the Mini Mental Status Examination (MMSE) should not be used as a screener for this population on the pre-test; however, $92 \%(n=119, Z=-8.835, p<.001)$ of participants correctly answered the question after the seminar. Second, prior to the seminar, $22 \%(n=29)$ of participants correctly answered a question about the length of time that $\mathrm{CRCl}$ may persist (the majority $[n=84,64 \%]$ underestimated the length of time); however, $74 \%(n=96, Z=-$ $7.267, p<.001)$ correctly answered the item on the post-test.

Table 2

Comparison of Pre-Seminar and Post-Seminar CRCI Knowledge Scores

\begin{tabular}{lccccccc}
\hline & $\mathbf{N}$ & $\begin{array}{c}\text { Pre-test } \\
\text { mean } \\
(\mathbf{S D})\end{array}$ & $\begin{array}{c}\text { Mann } \\
\text { Whitney } \boldsymbol{U} \\
(\mathbf{p} \text { value) }\end{array}$ & $\begin{array}{c}\text { Post-test } \\
\text { mean } \\
(\mathrm{SD})\end{array}$ & $\begin{array}{c}\text { Mann } \\
\text { Whitney } \boldsymbol{U} \\
(\mathbf{p} \text { value })\end{array}$ & $\begin{array}{c}\text { Wilcoxon } \\
\text { signed rank } \\
\text { test } \\
\mathbf{Z}(\mathbf{p} \text { value })\end{array}$ & $\begin{array}{c}\text { Effect } \\
\text { size } \\
\left(\mathbf{r}^{2}\right)\end{array}$ \\
\hline Total sample & 130 & $4.3(1.44)$ & & $8.44(1.48)$ & & $-9.623(<.001)^{\star *}$ & 0.84
\end{tabular}

\section{Years at current setting}

$\begin{array}{llllllll}<5 \text { Years } & 64 & 4.17(1.32) & & 8.42(1.41) & & -6.788(<.001)^{\star *} & 0.85 \\ \geq 5 \text { Years } & 64 & 4.45(1.54) & & 8.47(1.56) & & -6.729(<.001)^{\star *} & 0.84\end{array}$

\section{Total years practicing}
$<8$
$62 \quad 4.11(1.16)$
$8.39(1.55)$
$-6.611(<.001)^{* *}$
0.84
$\geq 8$
$66 \quad 4.50(1.64)$
0.14
$8.53(1.42)$
0.65

$-6.921(<.001)^{\star \star} \quad 0.85$


Table 2 Continued

\begin{tabular}{|c|c|c|c|c|}
\hline $\begin{array}{l}\text { Pre-test } \\
\text { mean (SD) }\end{array}$ & $\begin{array}{c}\text { Mann } \\
\text { Whitney U } \\
\text { (p value) }\end{array}$ & $\begin{array}{l}\text { Post-test } \\
\text { mean } \\
\text { (SD) }\end{array}$ & $\begin{array}{c}\text { Mann } \\
\text { Whitney U } \\
\text { (p value) }\end{array}$ & $\begin{array}{l}\text { Wilcoxon signed } \\
\text { rank test } \\
Z \text { ( } p \text { value })\end{array}$ \\
\hline
\end{tabular}

Present setting in the continuum of care
Acute care $\quad 41 \quad 4.20(1.53)$
$8.63(1.16)$
$-5.475(<.001)^{\star *}$
0.86

Inpatient

rehabilitation

$38 \quad 4.00(1.34)$

$8.11(1.90)$

$-5.122(<.001)^{\star *}$

0.83

Skilled

nursing

facility

$124.67(1.37)$

${ }_{a} 0.07$

$7.42(1.44)$

a0.012*

$-2.681(.007)^{\star \star}$

0.77

Outpatient $\quad 9 \quad 3.89(.93)$

$9.22(1.20)$

$-2.842(.007)^{\star *}$

0.95

Home health $\quad 10 \quad 5.10(1.52)$

$8.30(1.06)$

$-2.818(.005)^{\star \star}$

0.89

Community $20 \quad 4.65(1.50)$

$9.00(1.03)$

$-3.862(<.001)^{\star *}$

0.86

\section{Practitioner}

\begin{tabular}{|c|c|c|c|c|c|c|c|}
\hline OTR & 110 & $4.34(1.47)$ & & $8.61(1.38)$ & & $-8.91(<.001)^{\star *}$ & 0.85 \\
\hline СОТА & 20 & $4.10(1.29)$ & 0.50 & $7.50(1.67)$ & $.003^{\star \star}$ & $-3.67(<.001)^{\star *}$ & 0.82 \\
\hline
\end{tabular}

Encountered oncology population in clinical practice

$\begin{array}{lccccccc}\text { Yes } & 104 & 4.31(1.49) & 0.33 & 8.61(1.42) & 0.13 & -8.654(<.001)^{* *} & 0.85 \\ \text { No } & 15 & 3.93(1.28) & & 7.93(1.75) & & -3.309(.001)^{\star *} & 0.82\end{array}$

Note. OTR = Registered occupational therapist; COTA = certified occupational therapy assistant. ${ }^{*} \mathrm{P}<.05,{ }^{* *} \mathrm{p}<.01 . \mathrm{a}=$ Kruskal Wallis analysis was employed.

Practitioners' Perceived Impact of Seminar and Satisfaction

The majority $(n=125,98 \%)$ of participants perceived that the seminar increased their competence or knowledge related to $\mathrm{CRCl}$, and more than $96 \%(n=123)$ perceived that the seminar will have a positive impact on their performance when working with adults and older adults with $\mathrm{CRCl}$ in the future. The majority $(n=119,94 \%)$ of participants perceived that the seminar will have a positive impact on their future patient outcomes. The majority ( $n=125,98 \%)$ of participants were either "very satisfied" or "satisfied" with the seminar overall. Three participants $(2 \%)$ selected "neutral," and no participants selected "unsatisfied" or "very unsatisfied." Similarly, 122 (95\%) of participants either 
"strongly agreed" or "agreed" that the seminar effectively presented $\mathrm{CRCl}$ information; five participants (4\%) selected "neutral," one participant (1\%) selected "disagree," and zero participants selected "strongly disagree."

Additionally, 33 (25\%) participants provided additional comments on the seminar evaluation survey. Responses were categorized based on frequencies: praise for the program $(n=19,15 \%)$, desire for a longer course $(n=6,5 \%)$, requests for more resources provided on the handout $(n=3,2 \%)$, and elaboration on assessments and treatment information $(n=5,4 \%)$.

\section{DISCUSSION}

The purpose of this study was to comprehensively design, disseminate and examine the impact of implementing a face-to-face continuing education seminar designed to enhance occupational therapy practitioners' knowledge of $\mathrm{CRCl}$ in adults and older adults. It involved three steps: seminar development based on findings from a needs assessment, piloting the seminar with occupational therapy students, and delivering the seminar to occupational therapy practitioners. Results suggest that this face-to-face seminar was successful in significantly increasing occupational therapy practitioners' short-term knowledge related to $\mathrm{CRCl}$ and that it was a well-received method of dissemination. Additionally, the majority of participants perceived that the seminar increased their knowledge related to $\mathrm{CRCl}$ and anticipated that the seminar will improve their performance and patient outcomes in the future. These findings are consistent with other literature that has supported continuing education as an effective dissemination method for improving healthcare practitioners' knowledge (Byszewski et al., 2003; Horiuchi, Yaju, Koyo, Sakyo, \& Nakayama, 2009; Khatony, Nayery, Ahmadi, Haghani, \& Vehvilainen-Julkunen, 2009; McCluskey \& Lovarini, 2005).

Since there is presently $\mathrm{CRCl}$ clinically-relevant evidence that can impact occupational therapists' clinical practice, it is imperative that practitioners and educators continue to emphasize the importance of disseminating $\mathrm{CRCl}$ evidence through continuing competency opportunities in order to provide best practice to survivors of cancer. For example, the NCCN recommends against utilizing the MMSE, a cognitive screener used by occupational therapists (Radomski \& Morrison, 2014), since it is not sensitive enough to consistently screen cognitive impairments with this population (Denlinger, Ligibel, et al., 2014). Results of the pre-test revealed that only $30 \%(n=39)$ of practitioners were aware that they should avoid using the MMSE with survivors of cancer. As a second example, current evidence suggests $\mathrm{CRCl}$ may persist for years after cancer treatment completion (Asher \& Myers, 2015; de Ruiter et al., 2011; Koppelmans et al., 2012; Nguyen et al., 2013; Stouten-Kemperman et al., 2015; Yamada, Denburg, Beglinger, \& Schultz, 2010); however, this study found $84 \%(n=109)$ of participants underestimated the length of time that $\mathrm{CRCl}$ may persist prior to the seminar. Therefore, because practitioners will increasingly encounter cancer survivors (as a primary diagnosis or comorbid condition) throughout the continuum of care, these results illustrate the need to address gaps in practitioners' $\mathrm{CRCl}$ knowledge and support that face-to-face $\mathrm{CRCl}$ continuing competency seminars can be an effective approach for addressing knowledge gaps. 


\section{Implications for Occupational Therapy Education}

This study may have beneficial results for educators of occupational therapy students. Participants in the student pilot demonstrated a significant increase in their knowledge of $\mathrm{CRCl}$ in survivors of cancer. Educators developing occupational therapy curriculum should consider expanding beyond traditional diagnoses associated with cognitive impairments (i.e. stroke, traumatic brain injuries, dementia) and include conditions that may have side effects that may impair cognitive performance, as these are conditions that are highly likely to be encountered in clinical practice. The developed $\mathrm{CRCl}$ seminar included a section on factors that can contribute to $\mathrm{CRCl}$, such as medications (e.g. sedatives or steroids), sleep deficits, or psychosocial deficits. As there are a multitude of chronic conditions (outside of cancer) where these factors are applicable, this information is helpful for students to holistically examine factors that can affect cognitive performance and impede occupational engagement.

Since occupational therapy practitioners have reported challenges with their skills in obtaining and understanding evidence-based practice literature (i.e., difficulty searching the literature or lack of critical appraisal skills) on their own time, it is essential that occupational therapy educators continue to develop continuing competency opportunities (Bennett et al., 2003; Dysart \& Tomlin, 2002; McCluskey, 2003). Practitioners and organizations interested in developing additional continuing education projects may benefit from reviewing the description of this $\mathrm{CRCl}$ seminar's development process, particularly utilizing a needs assessment and piloting the seminar, to guide the development of other continuing education projects. The needs assessment served as a vital step to ensure that practitioners would be motivated to learn the content, as well as revealing additional topics that may be beneficial for practitioners to stay current in best practice. The needs assessment was also instrumental for guiding the design of the seminar. For example, many practitioners in the needs assessment indicated a desire for videos to improve their learning experience; therefore, in order to appeal to a diversity of learning preferences, the seminar was designed to be multimodal. Since previous literature additionally supports this (Vaughn \& Baker, 2001), occupational therapy educators may want to strongly consider conducting a needs assessment to guide the content and design of additional continuing education projects.

Practitioners and organizations interested in developing other continuing education projects may want to consider piloting to a small group prior to presenting to larger audiences. Piloting the study with a small group of occupational therapy students allowed for the project to be streamlined and fine-tuned. For example, following the pilot, it was determined the pre-test should be shortened from 18 to 10 items due to time constraints. Although students may take longer than practitioners to complete a pretest, valuable time during the seminar would have been lost due to filling out the program evaluation. Additionally, participants in the student pilot called for an expanded handout. The handout was subsequently doubled in its content, which many practitioners praised. 
When developing and delivering additional continuing competency opportunities on $\mathrm{CRCl}$ (or other continuing education topics), it may be beneficial to anticipate factors that may deter participation. For example, occupational therapy practitioners have reported that high costs of continuing competency programs or lack of time to attend programs due to work schedules can discourage continuing education participation (Dysart \& Tomlin, 2002). Nursing literature has also found that many practitioners have difficulty traveling to continuing education opportunities outside of work (Penz et al., 2007; Schweitzer \& Krassa, 2010). To address these barriers, this seminar was presented directly at the facility at a convenient time (selected by the facility). The seminar was presented at no cost and practitioners received free continuing competency credit to avoid excluding those who would be unable to attend due to limited personal or facility budgets. Therefore, lunch and learn opportunities may serve as a viable method for delivering continuing education information to practitioners.

\section{Future Work}

Although results only captured short-term knowledge gain and the anticipated outcomes on clinical practice, it is important to note that this was only a first step for facilitating knowledge translation. Knowledge translation refers to "the synthesis, exchange, and application of knowledge by relevant stakeholders to accelerate the benefits of global and local innovation in strengthening health systems and improving people's health" (World Health Organization, 2017). Knowledge translation is essential for improving clients' health status through a comprehensive multi-disciplinary process (Graham et al., 2006). Although there are many approaches to facilitate knowledge translation (Glasgow, Lichtenstein, \& Marcus, 2003; Grimshaw, Eccles, Lavis, Hill, \& Squires, 2012), continuing education is often viewed as an important first step in facilitating knowledge translation since it is focused on enhancing practitioners' clinical competence (Graham et al., 2006). Therefore, this study took an important first step in facilitating knowledge translation; however, future studies should include an interprofessional and comprehensive approach to optimize knowledge translation for practitioners and to improve service to delivery to survivors of cancer. Eight-seven percent $(n=113)$ of the sample indicated they had encountered the oncology population during their clinical practice; indicating that $\mathrm{CRCl}$ seminar may be clinically beneficial for many practitioners throughout the continuum of care. Although this study utilized a faceto-face method of dissemination, it may be beneficial for future studies to consider online delivery to increase accessibility and gather participation from more practitioners.

\section{Limitations}

This study had several limitations that future studies should consider. First, the seminar was piloted on students to identify challenges in the content and delivery of the seminar and make modifications to improve the seminar prior to presenting to practitioners. Although the student pilot was beneficial for identifying logistical errors, students have limited clinical knowledge and experience. Therefore, future studies may want to consider piloting continuing competency seminars at local state meetings or conferences in order to capture feedback from practitioners. Second, because the same 10-item knowledge questionnaire was used for the pre-test and the post-test, a pre-test interaction bias (pre-test heightened participants' sensitivity to information presented in 
the seminar) may have contributed to the score improvement. Third, the study sought participation from various settings throughout the continuum of care in a large metropolitan area; however, only $62.5 \%$ of facilities responded. Therefore, the sample pool of participants may have been biased because only one city was targeted and the facilities who responded to the email may be more likely to benefit from and promote continuing competency within their facilities. Fourth, there was an unequal distribution of practitioners in each setting; 43 participants represented the acute care setting, whereas the outpatient setting had nine participants. Thus, the results of this study cannot be generalized to all practitioners, and future studies should consider these methodological flaws when evaluating the effectiveness of continuing competency programs on long-term knowledge retention, behavioral service delivery changes, and capturing the impact of the continuing competency program clinical practice outcomes.

\section{CONCLUSION}

Occupational therapy is an important rehabilitation profession to holistically identify and address the distinct needs and functional limitations, including $\mathrm{CRCl}$, of survivors of cancer. With the increase in cancer survivorship, occupational therapy practitioners will continue to encounter survivors (even if cancer is not the referral diagnosis) throughout the continuum of care who may be experiencing functional deficits because of $\mathrm{CRCl}$. However, recent literature suggests that practitioners' $\mathrm{CRCl}$ knowledge needs are not fully met and that practitioners perceive the need for a face-to-face continuing competency seminar. This study took an important first step by developing and implementing a $\mathrm{CRCl}$ continuing competency seminar tailored toward occupational therapy practitioners and exploring its impact on short-term $\mathrm{CRCl}$ knowledge gain. Results suggested that (1) a CRCl seminar was an effective method for increasing practitioners' short-term knowledge of $\mathrm{CRCl}$; (2) practitioners perceived a positive effect on their current $\mathrm{CRCl}$ knowledge from the information delivered in the seminar; and (3) practitioners perceived a positive impact on both their future performance when working with cancer survivors and perceived patient outcomes. By facilitating knowledge translation, occupational therapy practitioners are better suited to apply current knowledge to improve cancer survivors' performance and participation.

\section{References}

Ahles, T. A., Root, J. C., \& Ryan, E. L. (2012). Cancer- and cancer treatmentassociated cognitive change: An update on the state of the science. Journal of Clinical Oncology, 30(30), 3675-3686. https://doi.org/10.1200/jco.2012.43.0116

Ahles, T. A., Schagen, S. B., \& Vardy, J. (2012). Clinical psycho-oncology. In L. Grassi \& M. Riba (Eds.), An international perspective. Wiley-Blackwell, Chichester (pp. 71-83). Somerset, New Jersey: John Wiley \& Sons.

Asher, A., \& Myers, J. S. (2015). The effect of cancer treatment on cognitive function. Clinical Advances in Hematology \& Oncology, 13(7), 441-450.

Bennett, S., Tooth, L., McKenna, K., Rodger, S., Strong, J., Ziviani, J., . . Gibson, L. (2003). Perceptions of evidence-based practice: A survey of Australian occupational therapists. Austalian Occupational Therapy Journal, 50(1), 13-22. https://doi.org/10.1046/j.1440-1630.2003.00341.x 
Boykoff, N., Moieni, M., \& Subramanian, S. K. (2009). Confronting chemobrain: An indepth look at survivors' reports of impact on work, social networks, and health care response. Journal of Cancer Survivors, 3(4), 223-232. https://doi.org/10.1007/s11764-009-0098-x

Byszewski, A. M., Graham, I. D., Amos, S., Man-Son-Hing, M., Dalziel, W. B., Marshall, S., . . . Guzman, D. (2003). A continuing medical education initiative for Canadian primary care physicians: The Driving and Dementia Toolkit: a pre-and postevaluation of knowledge, confidence gained, and satisfaction. Journal of the American Geriatrics Society, 51(10), 1484-1489. https://doi.org/10.1046/i.1532-5415.2003.51483.x

IBM Corp. (2013). IBM SPSS Statistics for Windows, Version 23.0. Armonk, NY: IBM Corp.

de Ruiter, M. B., Reneman, L., Boogerd, W., Veltman, D. J., van Dam, F. S., Nederveen, A. J., . . S Schagen, S. B. (2011). Cerebral hyporesponsiveness and cognitive impairment 10 years after chemotherapy for breast cancer. Human Brain Mapping, 32(8), 1206-1219. https://doi.org/10.1002/hbm.21102

Denlinger, C. S., Carlson, R. W., Are, M., Baker, K. S., Davis, E., Edge, S. B., . . . Freedman-Cass, D. (2014). Survivorship: Introduction and definition. Clinical practice guidelines in oncology. Journal of the National Comprehensive Cancer Network, 12(1), 34-45. https://doi.org/10.6004/inccn.2014.0005

Denlinger, C. S., Ligibel, J. A., Are, M., Baker, K. S., Demark-Wahnefried, W., Friedman, D. L., . . Freedman-Cass, D. A. (2014). Survivorship: Cognitive function, version 1.2014. Journal of the National Comprehensive Cancer Network, 12(7), 976-986. https://doi.org/10.6004/jnccn.2014.0094

Dysart, A. M., \& Tomlin, G. S. (2002). Factors related to evidence-based practice among US occupational therapy clinicians. American Journal of Occupational Therapy, 56(3), 275-284. https://doi.org/10.5014/ajot.2017.71S1-P06050

Edelstein, K., \& Bernstein, L. J. (2014). Cognitive dysfunction after chemotherapy for breast cancer. Journal of the International Neuropsychological Society, 20(4), 351-356. https://doi.org/10.1017/s1355617714000149

Forsetlund, L., Bjorndal, A., Rashidian, A., Jamtvedt, G., O'Brien, M. A., Wolf, F., . . . Oxman, A. D. (2009). Continuing education meetings and workshops: Effects on professional practice and health care outcomes. Cochrane Database Systematic Review(2), Cd003030. https://doi.org/10.1002/14651858.CD003030.pub2

Graham, I. D., Logan, J., Harrison, M. B., Straus, S. E., Tetroe, J., Caswell, W., \& Robinson, N. (2006). Lost in knowledge translation: Time for a map?. Journal of Continuing Education in the Health Professions, 26(1), 13-24. https://doi.org/10.1002/chp.47

Glasgow, R. E., Lichtenstein, E., \& Marcus, A. C. (2003). Why don't we see more translation of health promotion research to practice? Rethinking the efficacy-toeffectiveness transition. American Journal of Public Health, 93(8), 1261-1267. https://doi.org/10.2105/AJPH.93.8.1261

Grimshaw, J. M., Eccles, M. P., Lavis, J. N., Hill, S. J., \& Squires, J. E. (2012). Knowledge translation of research findings. Implementation Science, 7(1), 50. https://doi.org/10.1186/1748-5908-7-50 
Horiuchi, S., Yaju, Y., Koyo, M., Sakyo, Y., \& Nakayama, K. (2009). Evaluation of a web-based graduate continuing nursing education program in Japan: A randomized controlled trial. Nurse Education Today, 29(2), 140-149. http://doi.org/10.1016/..nedt.2008.08.009

Khatony, A., Nayery, N. D., Ahmadi, F., Haghani, H., \& Vehvilainen-Julkunen, K. (2009). The effectiveness of web-based and face-to-face continuing education methods on nurses' knowledge about AIDS: A comparative study. BMC Medical Education, 9(1), 41. https://doi.org/10.1186/1472-6920-9-4

Knowles, M. S., Holton III, E. F., \& Swanson, R. A. (2014). The adult learner: The definitive classic in adult education and human resource development. London: Routledge.

Koppelmans, V., Breteler, M. M., Boogerd, W., Seynaeve, C., Gundy, C., \& Schagen, S. B. (2012). Neuropsychological performance in survivors of breast cancer more than 20 years after adjuvant chemotherapy. Journal of Clinical Oncology, 30(10), 1080-1086. https://doi.org/10.1200/jco.2011.37.0189

Mariotto, A. B., Yabroff, K. R., Shao, Y., Feuer, E. J., \& Brown, M. L. (2011). Projections of the cost of cancer care in the United States: 2010-2020. Journal of the National Cancer Institute, 103(2), 117-128. https://doi.org/10.1093/jnci/dja495

McCluskey, A., \& Lovarini, M. (2005). Providing education on evidence-based practice improved knowledge but did not change behaviour: A before and after study. BMC Medical Education, 5, 40. https://doi.org/10.1186/1472-6920-5-40

McCluskey, A. (2003). Occupational therapists report a low level of knowledge, skill and involvement in evidence-based practice. Australian Occupational Therapy Journal, 50(1), 3-12. https://doi.org/10.1046/j.1440-1630.2003.00303.x

Nguyen, C. M., Yamada, T. H., Beglinger, L. J., Cavanaugh, J. E., Denburg, N. L., \& Schultz, S. K. (2013). Cognitive features 10 or more years after successful breast cancer survival: Comparisons across types of cancer interventions. Psychooncology, 22(4), 862-868. https://doi.org/10.1002/pon.3086

Penz, K., D'Arcy, C., Stewart, N., Kosteniuk, J., Morgan, D., \& Smith, B. (2007). Barriers to participation in continuing education activities among rural and remote nurses. Journal of Continuing Education in Nursing, 38(2), 58-66; 67-58, 93. https://doi.org/10.3928/00220124-20070301-03

Pergolotti, M., Williams, G. R., Campbell, C., Munoz, L. A., \& Muss, H. B. (2016). Occupational therapy for adults with cancer: Why it matters. Oncologist, 21(3), 314-319. https://doi.org/10.1634/theoncologist.2015-0335

Radomski, M. V., \& Morrison, M. T. (2014). Assessing abilities and capacities: Cognition. In M. V. Radomski \& C. A. T. Latham (Eds.), Occupational therapy for physical dysfunction (pp. 121-144). Baltimore, MD: Lippincott Williams \& Wilkins.

Reid-Arndt, S. A., Hsieh, C., \& Perry, M. C. (2010). Neuropsychological functioning and quality of life during the first year after completing chemotherapy for breast cancer. Psycho-Oncology, 19(5), 535-544. https://doi.org/10.1002/pon.1581

Schweitzer, D. J., \& Krassa, T. J. (2010). Deterrents to nurses' participation in continuing professional development: An integrative literature review. Journal of Continuing Education in Nursing, 41(10), 441-447. https://doi.org/10.3928/00220124-20100601-05 
Siegel, R., DeSantis, C., Virgo, K., Stein, K., Mariotto, A., Smith, T., ... Ward, E. (2012). Cancer treatment and survivorship statistics, 2012. CA: A Cancer Journal for Clinicians, 62(4), 220-241. https://doi.org/10.3322/caac.21149

Standards for Continuing Competence. (2015). American Journal of Occupational Therapy, 69(Supplement 3), 6913410055p1-6913410055p3. https://doi.org/10.5014/ajot.2015.696S16

Stouten-Kemperman, M. M., de Ruiter, M. B., Caan, M. W., Boogerd, W., Kerst, M. J., Reneman, L., \& Schagen, S. B. (2015). Lower cognitive performance and white matter changes in testicular cancer survivors 10 years after chemotherapy. Human Brain Mapping, 36(11), 4638-4647. https://doi.org/10.1002/hbm.22942

Ulfers, S. S., \& Berg, C. (2017). Occupational therapists with oncology exposure: Perceived needs on adults and older adults with cancer-related cognitive impairments. Occupational Therapy Journal of Research, 37(3), 149-154. https://doi.org/10.1177\%2F1539449217698105

Vaughn, L., \& Baker, R. (2001). Teaching in the medical setting: Balancing teaching styles, learning styles and teaching methods. Medical teacher, 23(6), 610-612. https://doi.org/10.1080/01421590120091000

World Health Organization. (2017). Knowledge Translation. Retrieved from http://www.who.int/ageing/projects/knowledge translation/en/

Yamada, T. H., Denburg, N. L., Beglinger, L. J., \& Schultz, S. K. (2010). Neuropsychological outcomes of older breast cancer survivors: Cognitive features ten or more years after chemotherapy. Journal of Neuropsychiatry and Clinical Neurosciences, 22(1), 48-54. https://doi.org/10.1176/appi.neuropsych.22.1.48 


\section{Appendix A: Pre and Post Test}

Please complete this page prior to today's seminar. Please circle only one answer.

1. Cancer-related cognitive impairments $(\mathrm{CRCl})$ are primarily found more in breast cancer survivors than other types of cancer survivors.
A. True
B. False

2. Chemotherapy is the primary cause of $\mathrm{CRCl}$.
A. True
B. False

3. What proposed percentage of cancer survivors experience long term cognitive deficits?
A. $30 \%$
B. $35 \%$
C. $40 \%$
D. $45 \%$

4. For individuals who developed cancer as an adult, what is the longest range of time that studies have suggested that cognitive deficits may persist?
A. 5-10 years
B. $10-20$ years
C. $20-30$ years
D. $30-40$ years

5. If an occupational therapist is wanting to briefly screen for $\mathrm{CRCl}$, it is recommended to use the Mini Mental Status Examination (MMSE).
A. True
B. False

6. The following assessments were designed to measure perceived cognitive changes throughout cancer rehabilitation. Which one of the following is not readily available to the public domain?
A. FACT-Cog
B. PROMIS-Applied Cognitive-Abilities
C. Attentional Fatigue Index

7. When evaluating the environment, which of the following assessments have been validated with the oncology population?
A. Safety assessment of function and the environment for evaluation (SAFER HOME)
B. Home Environment Assessment Protocol (HEAP)
C. In Home Occupational Performance Evaluation (IHOPE)
D. Cougar Home Safety Assessment

8. Studies evaluating individuals with $\mathrm{CRCl}$ who participated in cognitive training programs (primarily computer based programs) demonstrated improvement on objective neuropsychological testing and self-reported subjective cognitive performance.
A. True
B. False 
9. Studies evaluating individuals with $\mathrm{CRCl}$ who participated in cognitive rehabilitation programs demonstrated improvement on objective neuropsychological testing and selfreported subjective cognitive performance.

A. True

B. False

10. Studies evaluating individuals with $\mathrm{CRCl}$ who participated in exercise programs demonstrated improvement on objective neuropsychological testing and self-reported subjective cognitive performance.

A. True

B. False

Profession: $\square$ OT $\quad \square$ OTA $\quad \square$ PT/PTA $\quad \square$ SLP $\quad \square$ Other

\begin{tabular}{|c|c|c|c|c|c|}
\hline $\begin{array}{l}\text { Present primary } \\
\text { setting (heck }\end{array}$ & $\begin{array}{c}\text { Acute } \\
\text { Care }\end{array}$ & $\begin{array}{l}\text { Inpatient } \\
\text { Rehab }\end{array}$ & $\begin{array}{l}\text { Skilled } \\
\text { Nursing } \\
\text { Facility }\end{array}$ & Outpatient & Community \\
\hline
\end{tabular}
one):

If other, please describe:

- Number of years practicing at current setting:

- Total number of years practicing as a clinician:

- Have you encountered the oncology population before during your clinical practice?: $\square$ Yes $\quad \square$ No

1. How satisfied are you with today's seminar?

Very
Unsatisfied Unsatisfied Neutral Satisfied Very Satisfied

2. The seminar effectively presented $\mathrm{CRCl}$ information:

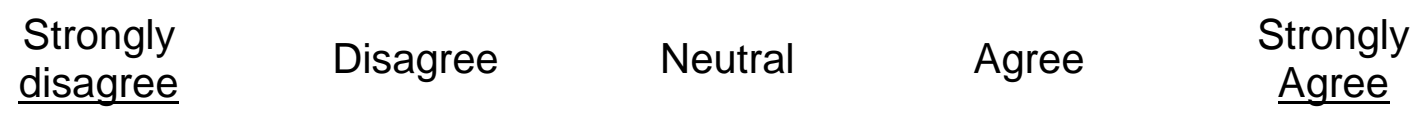


3. Please mark the projected impact of this seminar on your competence, performance, and patient outcomes:

- How much will this seminar increase your competence or knowledge related to CRCl:
$\square$ No Increase
$\square$ Moderate Increase
$\square$ Great Increase

- How much will this seminar increase your performance when working with adult/ older adult cancer survivors:
$\square$ No Increase
$\square$ Moderate Increase
$\square$ Great Increase

- How much will this seminar increase or improve your patient outcomes:

$\square$ No Increase $\quad \square$ Moderate Increase $\quad \square$ Great Increase

4. Please list any general suggestions or areas for improvement: 